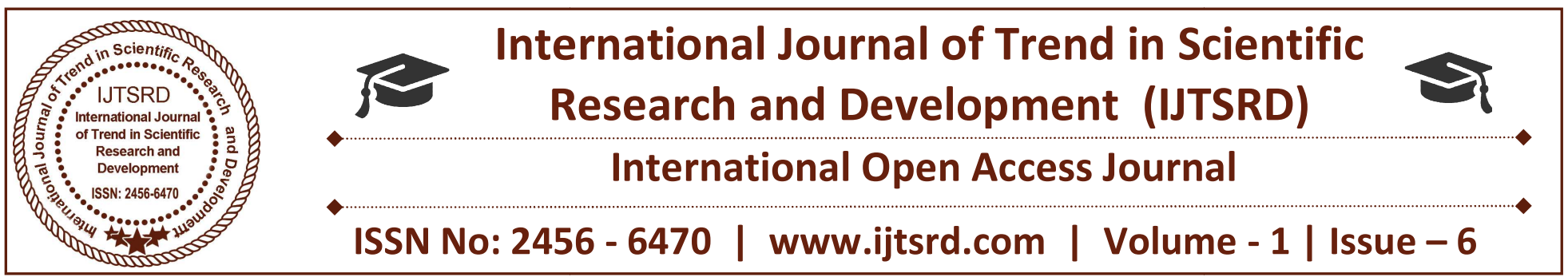

\title{
Review on Experimental Analysis of Matrix Absorber Designs for Solar Air Heater
}

\author{
Arjun Thakre \\ M.E. Scholar,Mechanical Engg., \\ Radharaman Institute of \\ Technology and Science, \\ Bhopal, M.P.
}

\author{
Ajay Singh \\ Head and Professor, Department of \\ Mechanical Engg., Radharaman \\ Institute of Technology and \\ Science, Bhopal, M.P.
}

\author{
Ashish Verma \\ Assistant Professor, Department of \\ Mechanical Engg., Radharaman \\ Institute of Technology and \\ Science, Bhopal, M.P.
}

\section{ABSTRACT}

Solar energy is important source of renewable energy. This energy are used in solar air heater. Solar air heater is one of the valuable heat sources with variety of applications such as space heating, industrial process heating and drying of fruits and vegetables etc. The thermal efficiency of a conventional solar air heater $(\mathrm{SAH})$ can be improved by reducing the losses from the collector surface by using proper insulation and increasing the convective coefficient between heat collecting surface and working fluid by increasing the heat transfer area which can be increased by double pass design. Some experimental and theoretical investigations have been considered to enhance the performance of double pass solar air heaters (DPSAHs) provided with performance enhancement techniques i.e. using packed bed materials (PBMs), extended surfaces like fins, and corrugated/grooved absorbing surfaces. The objective of present study is to review the various investigations conducted on performance enhancement of solar air heater. Based on the review, it is found that the most of the investigations were performed on double pass system having PBM and integrated with extended surfaces. Thermal efficiency of double pass solar air heater with porous media is higher than single pass and double pass solar air heater without porous media. Effect of various parameters of porous media like pitch, number of layers, bed depth, porosity, thermal conductivity, pitch to wire diameter ratio have been studied. Few studies were conducted on corrugated or grooved absorbing surface and very few studies have been presented on double pass systems having artificial roughness.

Keyword: solar air heater, fins, thermal efficiency, porous media

\section{INTRODUCTION}

Energy plays an important role in worldwide economic growth and industrialization. It is available in many forms. For the growth of the world industry play important role and industry are run by energy. Environment degradation with use of fossil fuels is a danger to life in this earth. For better life on earth depletion fossil fuel reserves and environmental threats, we need to develop the renewable energy sources. It is well known that solar energy is an infinite resource on the earth. The sun produces a vast amount of energy which can be collected through a system and then it converted into heat or electricity. Humans have harnessed the energy of the sun for billions of years. In the fifth century BC, the Greeks took affair advantage of this energy through designing their buildings to capture the sun's heat maximum in cold climatic conditions. After that, the Romans has been put their efforts to improve the architecture of 
buildings by covering southward windows with a transparent glass to avoid the escape of solar heat captured in the sunshine hours. Solar energy can be utilized by several ways. Among many renewable energy sources, solar energy is huge energy source for fulfill the demand. The freely available solar radiation provides an infinite and non-polluting reservoir of fuel. The easiest way to utilize solar energy for heating applications is to convert it into thermal energy by using solar heater.

In low temperature application Flat-plate solar collectors are extensively used and it attracted the attention of a large number of investigators. Several designs of solar air heaters have been developed over the years in order to improve their thermal efficiency and performance. Basically, there are two types of flat-plate solar heating collectors; water heating collectors and air heating collectors. The development of air heating collector is slow compared to water heating collector mainly due to lower thermal efficiency and design limitation. Conventional solar air collectors have poor performance due to high heat losses and low convective heat transfer coefficient between flowing air stream and the absorber plate. Attempts have been made to improve the thermal efficiency of conventional solar air collectors by using various design and arrangements of flow.

Greenhouse heating by solar air heaters on the roof setup are studied [20]. By using porous packing material in the duct of solar air heater is one of the methods to improve the thermal efficiency [10]. The double-duct flow mode of solar air heater has the advantage of reducing the heat losses and provides improvement in thermal efficiency with marginally increasing the heater size or cost [13]. A number of analytical and experimental studies have been carried out with packed bed, fins integrated double pass solar air heater which shows significant increase of the performance compared to the conventional system [12]. Few studies have been reported with corrugated absorber surface [3]. Different patent design is used in much research paper [6]. Integration of transparent insulation materials into solar collector devices are also used [7]. Comparative Study of ThermoHydraulic Performance of Artificially Roughened Solar Air Heaters are analyzed [8].

\section{Design of different types of matrix}

The solar thermal absorbers material is to absorb, to store and to transfer the thermal energy received from solar radiation to heat transfer medium such as air, water and other fluid .Its performance relies on the material type and its thermo-physical properties as well as coating of the absorber surface. Heat transfer coefficient value of air is four times less compared to water and this directly affects the thermal efficiency when it comes to transferring heat between absorber plate and the flowing air. In order to enhance the efficiency, various designs of absorbers and enhancement have been proposed. In some researcher used phase change material for better thermal performance [4]. Three methods that can be used to enhance the heat transfer for air solar absorber are the implementation of secondary heat transfer surface, disruption of the unenhanced fluid velocity and disruption of the laminar sub layer in the turbulent boundary layer [17]. By introducing turbulent flow in the flow path of the solar air collector, a significant increase of collector performance is recorded [17]. This is due to higher heat transfer coefficient and increased contact surface between air and absorbers which increase the heat transport from the absorber to heat transfer fluid. Solar air collectors can be classified according to its movement on axis as well as the type of absorbers used in the solar air collector and base design geometry namely flat absorbers, tubular absorbers and point absorbers [17]. Further differentiation for solar air collector with flat absorbers, also known as non-concentrating absorber, can be made based on the physical properties of the absorbers, which are non-permeable or permeable absorbers. Thermal absorber design for stationary flat absorber is based on bare-flat plate orientation where it lies on the flat plane with no concentrating points. Non-permeable absorbers indicate the flat absorbers with non-permeable material and that it is possible to have extended versions of this absorber e.g. corrugated, finned and/or assistance of flow redirection. The enhancement method of permeable absorbers are the same as non- permeable absorbers except that it has two absorber sub-types which are matrix/meshes and perforated type[16]. The classical design of solar absorber are flat plate, V-groove, packed bed and matrix/meshes[10,16,28]. From these base designs, a few variations of new absorbers were invented to increase the performance of solar air collector. Absorber enhancement can be generalized into two common types which are corrugated and finned [3, 12]. Further enhancement can expand into flow redirection method where air in- flow in the solar air collector is diversified by means of diversion of air flow path [18]. Absorber designs with significant 
efficiency improvement over conventional flat-plate solar air collect or have been proposed by various authors [10,11, 13, 15]. With more advanced and complex design of absorbers, the cost of fabrication and manufacturing would also increase [19]. Performance of solar air absorbers is greatly influenced by the air flow behavior in the solar air collector [22]. Different type so fair flow redirection applicable for solar air collectors designs are identified as front pass, back pass, parallel pass and double pass etc. $[12,15,18]$. Variations have been made by many researchers in terms of air flow redirection methods specified above with the objective to optimize the designs and to increase the performance of solar air collector $[5,10,12]$.The permeable of solar air collector permeable absorber can be categorized into many types which are $\mathrm{V}$
Groove, baffled fin, matrix and aluminum cans etc. $[10,12,13,15]$. The types of permeable absorbers as listed above differ in their operational configuration, and vary in terms of absorber topology, arrangement and material used for the absorber. Radiative losses from the absorber can be minimized by applying selective coating on the absorber. Adding flow obstructions such as fins and baffles in the collector increases the surface contact area and may induce higher turbulence in air flow, yet but with such method, an increase of pressure drop is expected which leads to loss of efficiency [9, 13, 14]. Performance and Cost Aspect of Double Pass V Groove Absorber with and without Porous Media are viewed [21].

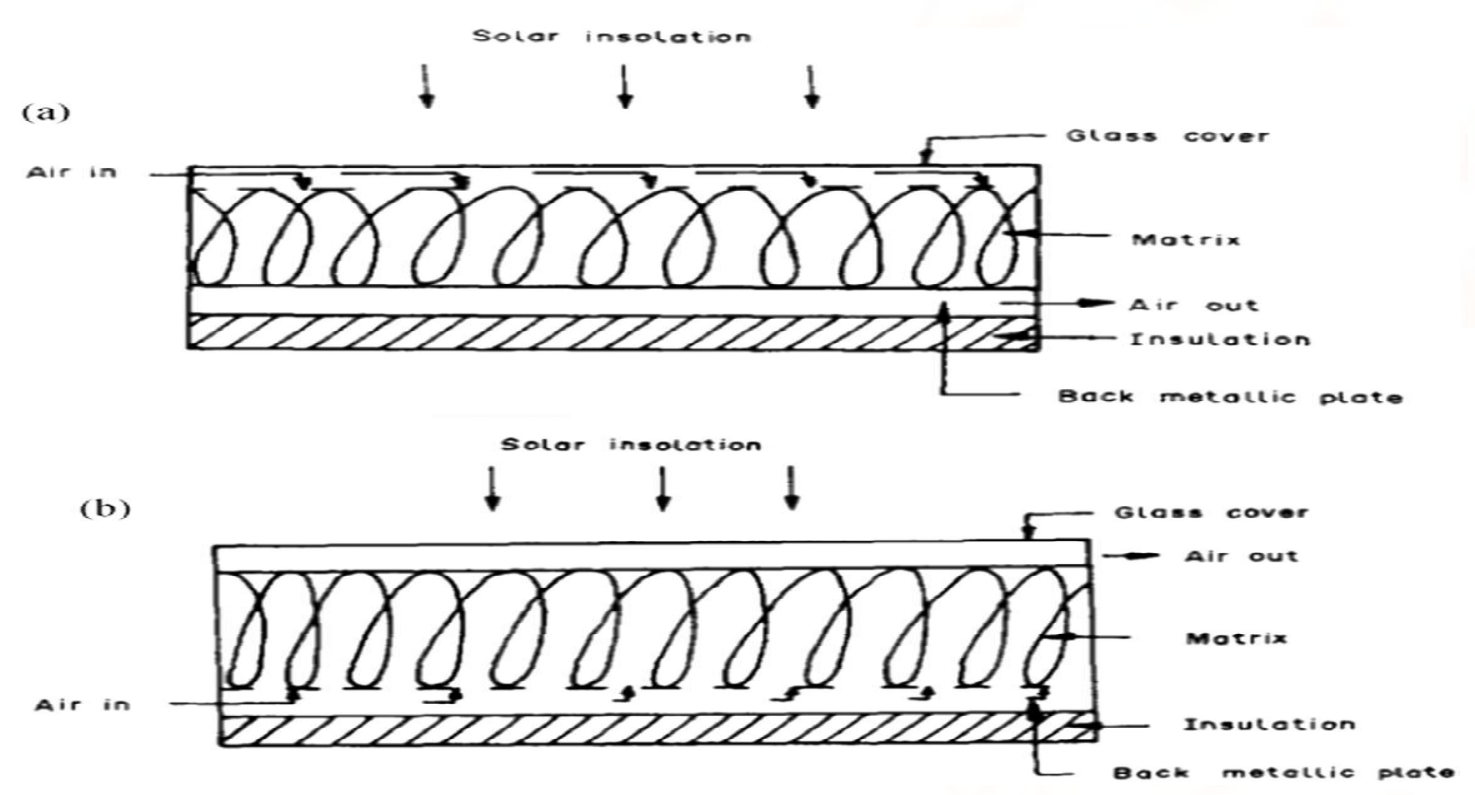

Fig - 1

\section{Design of solar air collector}

Despite improvements on the absorber design for nonpermeable absorbers, top losses especially radiative losses from the absorber plate are imminent. Applying selective coating at the cover could reduce the losses but the overall solar air collector efficiency is also affected. Introduction of obstacles, for example, baffles and fins could increase the heat transfer coefficient at absorber and air flow, but this would also cause a high pressure drop at the solar air collector. Another short coming of the non-permeable absorber is its ability to absorb the solar radiation is restricted by the available surface area of absorber through a thin air layer. With permeable absorber type, solar radiation travels further into the matrix and higher surface is exposed to radiation increasing the total energy gained by the absorber. The heat is transferred to the air stream flowing through the matrix absorber with lower pressure drop. The configuration of matrix porosity index and the thickness of matrix are significant to the matrix design because over or under sizing the parameters could lead to a reduction on overall efficiencies [2]. Advantages of matrix absorber over other are described $[1,2]$. Amongst the advantages is that solar radiation penetration depth and absorption depends on the thickness of matrix layers and extinction coefficient. Further, increase exposure of heat transfer 
surface area of matrix absorber to the air flow ensuing higher heat transfer rate. Also, effective air flow disruption in the matrix will cause improved heat transfer coefficient and finally, its ability to operate at low operating temperature subsequently will reduce heat loss. A double pass solar air collector incorporating permeable matrix absorber at second pass is designed to increase the efficiency of collector up to $55 \%[16]$. It was highlighted that careful consideration must be given on the design of bending from first to the second pass if using a highly permeable matrix to minimize pressure drop, hence increasing total collector efficiency. A simplified and well described mathematical modeling for a double pass with matrix absorber was presented in his work.

(a)

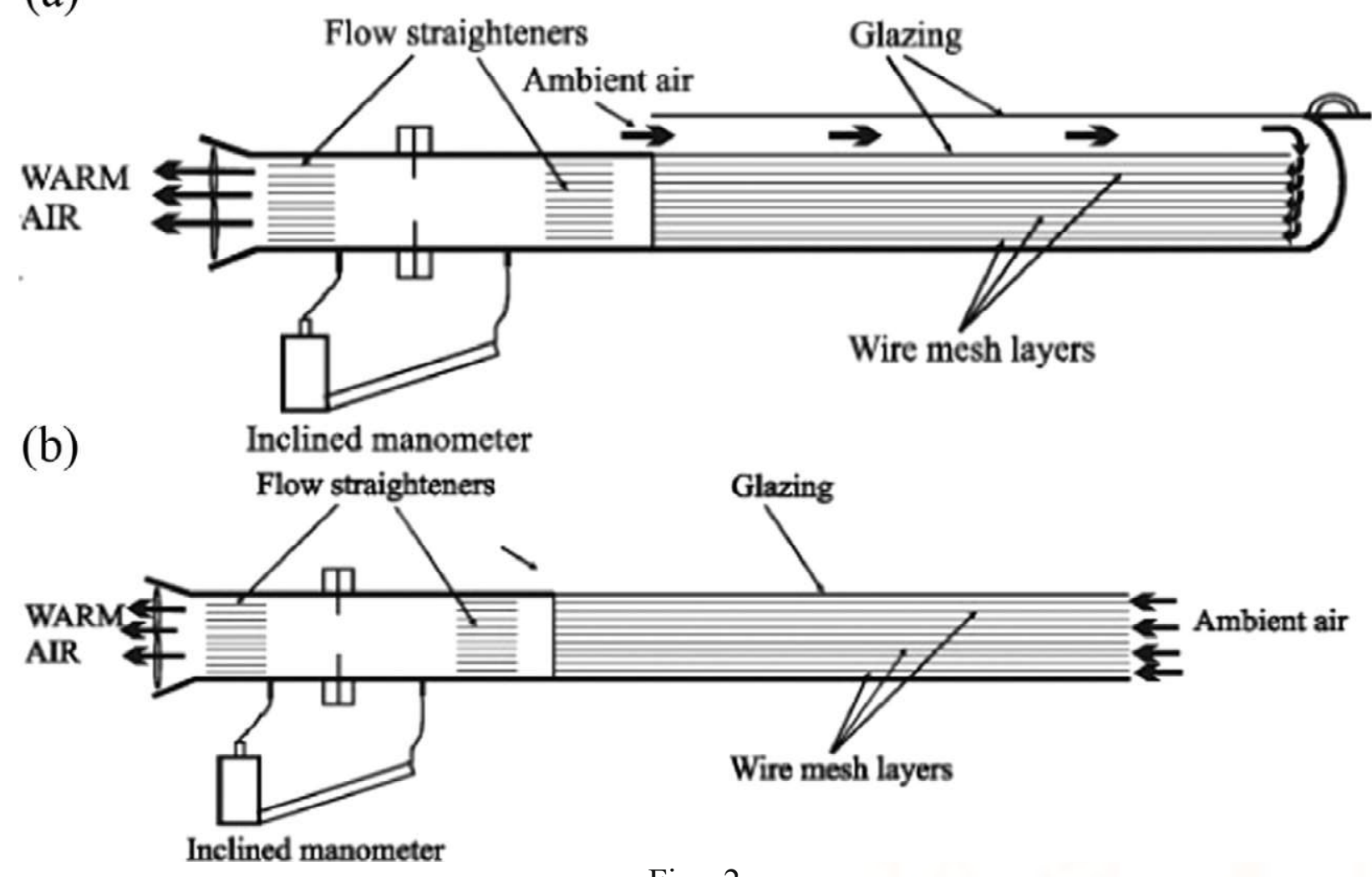

Fig - 2

The matrix solar air collector with 2 modes of air flow direction with one mode presenting the air is flowing downward and second mode presenting the air is flowing upward from inlet to outlet port respectively. Matrix absorber comprises of iron foils by-product from lathe. The energy balance for both modes is differentiated by changing the sign of the mass flow rate parameter, where upward mode is assigned with a positive sign of mass flow rate and vice versa. The efficiency of matrix solar air collector with upward mode exhibited on average $50 \%$ compared with the downward mode of $22 \%$. An earlier investigation by Sharma [26] concluded that matrix solar air collector with a similar, revealed the tendency to maintain constant efficiency at higher mass flow rate.

\section{CONCLUSIONS}

Matrix absorber for solar air collector has a large scope for further development in terms of its technical prowess. Although matrix absorber has existed several design and its improvement as compared to other absorber types especially non-permeable absorbers. Low cost and high thermal absorber material with optimal thermo-physical characteristics is preferable for matrix absorber without 
compromising the performance of the collector. Improvement in Performance is also possible with combination of absorber materials, coalescence with other type of absorbers and type of flow used. In conclusion, compact matrix absorber design, high efficiency and high energy gain is the main stream direction for matrix absorber development. Matrix absorber performance is strongly influenced by the geometrical parameters, matrix porosity index, matrix thickness, type of fluid use, surface density and material thermo-physical properties. These attributes must be critically evaluated in the development of matrix thermal absorber, where by excessive implementation of enhancement method such as fins and flow redirection could lead to reduce the performance and consequently to solar air collector.

\section{REFERENCES}

[1]. Review on matrix thermal absorber designs for solar air collector A.A.Razak , Z.A.A.Majid , W.H.Azmi , M.H.Ruslan , G.Najafi , K. Sopian.

[2]. Matrix solar air heaters - A review $\mathrm{K}$. Rajarajeswari, A.Sreekumar.

[3]. A parametric study on the thermal performance of cross-corrugated solar air collectors.

[4]. Solar air heater with phase change material: An energy analysis and acomparative study Aymen El Khadraoui, Salwa Bouadila, Sami Kooli, Amenallah Guizani, Abdelhamid Farhat.

[5]. Thermal Performance of Recycle Pass Solar Air Heater with V... Article September 2016.

[6]. A Review of Recent Patents on Solar Air Heaters Article. April 2015.

[7]. Integration of transparent insulation materials into solar collector devices. Julian D. Osorio, Alejandro Rivera-Alvarez , Philibert Girurugwiro, Sam Yang , Rob Hovsapian

[8]. Comparative Study of Thermo-Hydraulic Performance of Artificially Roughened Solar Air Heaters Conference Paper February 2014.

[9]. Performance Analysis of Double Pass Solar Air Heater with Bottom Extended Surface. Rudra Nandan Pramanika,, Sudhansu Sekhar Sahoob, Ranjan Kumar
Swainc,Tara Prasad, Mohapatraa, Ashis Kumar Srivastava.

[10]. Performance and Cost Aspect of Double Pass V Groove Absorber with and without Porous Media Article · December 2016.

[11].Experimental investigation on performance of a double pass artificial roughened solar air heater duct having roughness elements of the combination of discrete multi V shaped and staggered ribs. Ravi Kant Ravi, R.P. Saini Alternate Hydro Energy Centre, Indian Institute of Technology Roorkee, Roorkee, Uttarakhand 247667, India.

[12]. Collector Efficiency by Single Pass of Solar Air Heaters with and without Using Fins Foued Chabane, Noureddine Moummi, Said Benramache, Djamel Bensahal and Okba Belahssen.

[13].Performance Study of Solar Air Heater with Baffled Duct. B.K. Maheshwari, Rajendra Karwa, R. Singhvi, A. Goyal, R.N. Kumawat, A. Sharma, R. Prajapat, D. Kumawat, M. Rankawat, N. Bhardwaj.

[14].Foued CHABANE, Nesrine HATRAF, Noureddine MOUMMI Experimental study of heat transfer coefficient with rectangular baffle fin of solar air heater.

[15].Experimental investigation of thermal performance of a double-flow solar air heater having aluminium cans. Filiz Ozgen, Mehmet Esen, Hikmet Esen.

[16].Recycle Effect on Device Performance of Wire Mesh Packed Double-Pass Solar Air Heaters. ChiiDong Ho, Chun-Sheng Lin, Tz-Jin Yang and ChunChieh Chao.

[17].A thermodynamic review of solar air heaters. Abhishek Saxena, Varun, A.A.El-Sebaii Faculty of Mechanical Engineering ,M.I.T., Moradabad244001 ,India.Faculty of Mechanical Engineering, N.I.T., Hamirpur177005, India c Physics Department, Faculty of Science, Tanta University, Tanta ,Egypt.

[18].Performance of a double pass solar air collector. B.M. Ramani, Akhilesh Gupta, Ravi Kumar .

[19].Low cost solar air heater. R.S. Gill, Sukhmeet Singh, Parm Pal Singh.

[20].Greenhouse heating by solar air heaters on the roof. Khalid A. Joudi, Ammar A. Farha. 
[21]. Performance and Cost Aspect of Double Pass V [26]. Sharma V K, Rizzi, Garg. Design and Groove Absorber with and without Porous Media. Article December 2016. development of a matrix type solar air heater.EnergyConversManag1991;31:379-88.

[22]. Thermal efficiency analysis of a single flow solar air heater with different mass flow rate in a smooth plate. Foued Chabanea, Noureddine Moummi, Abdelhafid Brima, Said Benramache.

[23]. A Review of Solar Air Heaters using wire Mesh Absorber Samir Dhatkar, Ankit Khandelwal, Kanase-Patil

[24].Efficiency Enhancement of Two Pass Solar Collector with Steel Matrix in the Region of Rajshahi, Bangladesh Article May 2017.

[25].Review of solar air collectors with thermal storage units.Mahmud M. Alkilani , K. Sopian, M.A. Alghoul, M. Sohif, M.H. Ruslan.

[27]. Experimental Investigation of Single Pass Solar Air heater With and Without Square Steel Wire Mesh on Absorber plate Conference Paper December 2016.

[28].Single and double pass solar air heaters with wire mesh as packing bed. L.B.Y. Aldabbagh, F. Egelioglu, M. Ilkan.

[29].Comparative study of solar air heater performance with various shapes and configurations of obstacles Kishor Kulkarni1, Kwang-Yong Kiml. 